\title{
Characterizing Glioblastoma Heterogeneity via Single-Cell Receptor Quantification
}

\author{
Si Chen ${ }^{1}$, Thien Le ${ }^{2}$, Brendan A. C. Harley ${ }^{3,4}$ and P. I. Imoukhuede ${ }^{1,4,5 *}$ \\ ${ }^{1}$ Department of Bioengineering, University of Illinois at Urbana-Champaign, Champaign, IL, United States, ${ }^{2}$ Department of \\ Mathematics and Department of Computer Science, University of Illinois at Urbana-Champaign, Champaign, IL, \\ United States, ${ }^{3}$ Department of Chemical and Biomolecular Engineering, University of Illinois at Urbana-Champaign, Urbana, \\ IL, United States, ${ }^{4} \mathrm{Carl}$ R. Woese Institute for Genomic Biology, University of Illinois at Urbana Champaign, Urbana, IL, \\ United States, ${ }^{5}$ Department of Biomedical Engineering, Washington University, St. Louis, MO, United States
}

\section{OPEN ACCESS}

Edited by:

Paul De Vos,

University Medical Center Groningen,

Netherlands

Reviewed by:

Alessandro Poggi,

Dipartimento delle Terapie

Oncologiche Integrate, Ospedale

Policlinico San Martino, Italy

Cristiana Tanase,

Victor Babes National Institute of

Pathology, Romania

*Correspondence:

P. I. Imoukhuede

pimoukhuede@wustl.edu

Specialty section: This article was submitted to Biomaterials,

a section of the journal Frontiers in Bioengineering and Biotechnology

Received: 13 March 2018 Accepted: 21 June 2018 Published: 11 July 2018

Citation:

Chen S, Le T, Harley BAC and Imoukhuede PI (2018) Characterizing Glioblastoma Heterogeneity via Single-Cell Receptor Quantification. Front. Bioeng. Biotechnol. 6:92. doi: 10.3389/fbioe.2018.00092
Dysregulation of tyrosine kinase receptor (RTK) signaling pathways play important roles in glioblastoma (GBM). However, therapies targeting these signaling pathways have not been successful, partially because of drug resistance. Increasing evidence suggests that tumor heterogeneity, more specifically, GBM-associated stem and endothelial cell heterogeneity, may contribute to drug resistance. In this perspective article, we introduce a high-throughput, quantitative approach to profile plasma membrane RTKs on single cells. First, we review the roles of RTKs in cancer. Then, we discuss the sources of cell heterogeneity in GBM, providing context to the key cells directing resistance to drugs. Finally, we present our provisionally patented qFlow cytometry approach, and report results of a "proof of concept" patient-derived xenograft GBM study.

Keywords: single-cell, glioblastoma, RTK, heterogeneity, VEGFR, EGFR, IGFR, stem cell

\section{INTRODUCTION}

GBMs are the most frequent and lethal malignant primary adult brain tumor (Yadav et al., 2018), which presents a critical need to develop new therapeutics. Addressing the dysregulation of RTK signaling pathways offers promise in overcoming GBM lethality (Hawkins-Daarud et al., 2013; Cloughesy et al., 2014; Smith et al., 2016; Massey et al., 2018). RTK dysfunction has been observed in GBM, where these pathways are correlated with tumor cell proliferation (Johnson et al., 2012; Furnari et al., 2015), angiogenesis (Plate et al., 1994; Kuczynski et al., 2011), tumor invasiveness (Giannini et al., 2005; Sangar et al., 2014), and resistance to therapy (Murat et al., 2008; Lu and Bergers, 2013; Popescu et al., 2015). Moreover, these pathways are popular targets for smallmolecule inhibitors (Rich and Bigner, 2004; Candolfi et al., 2011). Unfortunately, the clinical benefit of these targeted therapies is limited by drug resistance (De Witt Hamer, 2010; Szopa et al., 2017).

Increasing evidence suggests that drug resistance may be attributed to tumor heterogeneity (variations within an individual tumor) (Saunders et al., 2012; Furnari et al., 2015; Qazi et al., 2017). For example, a landmark study identified tumor subpopulations resistant to therapy prior to treatment by sequencing 4,645 single cells from 19 melanoma patients. This thorough analysis was enabled by single-cell technology, and may have been overlooked with ensemble sequencing (Tirosh et al., 2016). Additionally, a single-cell analysis of patient-derived xenografts (PDXs) of GBM39 also found higher heterogeneity in resistant tumors than in responsive tumors (Shi et al., 2012). In line with these single-cell measurements, we previously discovered, measured, 
and statistically described heterogeneity in breast cancer xenografts by quantifying vascular endothelial growth factor plasma membrane receptor (VEGFR) concentrations at the single-cell level (Imoukhuede and Popel, 2014). When we combined this quantitative analysis with computational modeling, we arrived at the prediction that tumors having "high" concentrations of plasma membrane VEGFR1 could be resistant to anti-VEGF drugs (angiogenesis inhibitors) (Weddell and Imoukhuede, 2014). Clinical work supports this prediction for colorectal cancer (Weickhardt et al., 2015), and application of this quantification and prediction should offer a new paradigm for biomarker discovery in cancer medicine.

To address the need for quantitative, single-cell analysis of GBM heterogeneity, we apply our optimized and provisionally patented VEGFR quantitative flow (qFlow) cytometry approach to GBM (Imoukhuede and Popel, 2011, 2014; Imoukhuede et al., 2013; Weddell and Imoukhuede, 2014; Chen et al., 2015, 2017; Imoukhuede and Chen, 2018). We describe expanded measurement to several RTKs critical to tumor development. To provide further context we, briefly, review the roles of RTKs in cancer and present connections between RTK heterogeneity and drug resistance. We then present our approach, qFlow cytometry, and report promising findings of a "proof of concept" PDX GBM study.

\section{ROLES OF RTKS IN CANCER}

RTKs are widely expressed transmembrane proteins (Cadena and Gill, 1992; Ferrara et al., 2003). Upon ligand binding, they are activated via canonical (Mac Gabhann and Popel, 2007; Sarabipour and Hristova, 2016) and non-canonical (Steinkamp et al., 2014; Chen et al., 2015; Pennock et al., 2016; Mamer et al., 2017) ligand-induced dimerization and tyrosine phosphorylation mechanisms. Importantly, unligated receptors can dimerize (Ruch et al., 2007; Chung et al., 2010; LowNam et al., 2011; Lin et al., 2012; Comps-Agrar et al., 2015; King et al., 2016; Sarabipour and Hristova, 2016; Sarabipour et al., 2016) and signal (Wu et al., 2010; Sarabipour et al., 2016; Kazlauskas, 2017), although ligand binding stabilizes the dimeric receptor structure. These receptor-initiated signaling events regulate cell survival, proliferation, differentiation, and motility (Hubbard and Miller, 2007; Volinsky and Kholodenko, 2013).

VEGFRs are upregulated in many cancers (Ferrara, 2002; Kut et al., 2007; Mac Gabhann and Popel, 2008). Signals through endothelial VEGFRs and the neuropilin (NRP) co-receptors (Imoukhuede and Popel, 2011, 2012, 2014; Imoukhuede et al., 2013; Gelfand et al., 2014) induce the sprouting angiogenic hallmarks of cell proliferation and cell migration (Simons et al., 2016). These sprouting angiogenesis hallmarks also sustain tumor growth and enable tumor metastasis (Hanahan and Weinberg, 2011; Shibuya, 2014). VEGF and other pro-angiogenic factors, may also regulate vascular growth and regression in tumors that co-opt pre-existing blood vessels (Holash et al., 1999; Jayson et al., 2016; Kuczynski et al., 2016).

In addition to these canonical pathways, cross-family signaling may also affect tumor vascularization. In this paradigm, ligands from one growth factor family bind to and signal through receptor(s) of another family. For instance, we have shown VEGF-mediated downregulation of PDGFRs (Chen et al., 2015), and discovered that both VEGF-PDGFR binding and PDGFVEGFR binding is high affinity (Mamer et al., 2017). Other cross-family studies have identified VEGF-PDGFR binding and signaling (Ball et al., 2007; Pennock et al., 2016) and VEGFRPDGFR dimerization in tumor associated pericytes (Greenberg et al., 2008). Altogether, these canonical and cross-family RTK mechanisms suggest several possible receptor activation landscapes that can contribute to tumor growth and drug resistance.

\section{GBM-ASSOCIATED CELL HETEROGENEITY: STEM AND ENDOTHELIAL}

An accepted origin of tumor heterogeneity involves clonal evolution; an reiterative process of genetic mutation, clonal selection, and expansion, which drives the growth of single cancer cells into heterogeneous tumor masses (Greaves and Maley, 2012; Greaves, 2015; McGranahan and Swanton, 2017). In addition to cancer cells, other cell types within the tumor may also differentiate or transition as tumor develops. Some such cells include: tumor-associated fibroblasts, macrophages/monocytes, endothelial cells (ECs), and stem cells (Saunders et al., 2012). Here, we describe glioblastoma stem cells (GSCs) and ECs, which we focus on in our pilot study.

GSCs are an important tumor cell component, because despite their small number $(\sim 0.5-10 \%)$ (Pallini et al., 2011), GSCs are more resistant to radiotherapy and chemotherapy than other cancer cells (Schonberg et al., 2014; Seymour et al., 2015). Furthermore, their resistance can amplify tumor heterogeneity, because they have self-renewing and tumor-initiating capabilities (Lathia et al., 2015). GSCs are often identified by CD133 (Mak et al., 2011), which is associated with poor prognosis in a number of tumor types. There is controversy surrounding the usage of CD133 as a GSC marker (Golebiewska et al., 2013; Seymour et al., 2015; Bradshaw et al., 2016). Early studies showed a subpopulation of GBM cells expressing CD133 were able to form tumors (Singh et al., 2004) and further studies showed subpopulations of $\mathrm{CD} 133^{-}$cells were also able to form tumors in vivo (Beier et al., 2007). While these studies do not negate the possible role of CD133 in identifying GSCs, they do highlight the importance of heterogeneity and the need for additional markers. Therefore, establishing a "barcode" of RTK plasma membrane concentrations on GSCs may help to identify novel markers, aiding in the isolation and understanding of these stem cells.

ECs, the primary structural unit of the vasculature, are an important contributor to GBM development. Unlike normal vessels, tumor vasculature is leaky, tortuous, and dilated (Jain, 2005; Aird, 2009). In addition to typical tumor vascular pathological features, brain tumor vasculature exhibits the loss of the important blood-brain-barrier feature of tight EC-EC junctions when tumor size grows beyond $1-2 \mathrm{~mm}$ in diameter 
(Jain et al., 2007). The close interaction between tumors and tumor vessels, and the observation of extensive EC heterogeneity supports the need for profiling tumor-associated ECs.

\section{A PARADIGM SHIFT IN SINGLE-CELL TECHNOLOGIES: FROM GENE-CENTRIC TO PROTEOMICS}

Studies characterizing GBM heterogeneity primarily focus on genetic and transcriptomic profiling (Verhaak et al., 2010; Snuderl et al., 2011; Dunn et al., 2012; Szerlip et al., 2012; Brennan et al., 2013; Patel et al., 2014; Ellis et al., 2015), which does not always correlate with functional changes (Simonson and Schnitzer, 2007; Feng et al., 2009; Taniguchi et al., 2010). Moreover, multiple studies show discordance between sequence data and protein expression in GBM, particularly with regards to epidermal growth factor receptor (EGFR) (Brennan et al., 2009) and PDGFR (Hermanson et al., 1992) gene vs. protein expression. Because proteins are the effectors of signaling toward functional response (Grecco et al., 2011; Imoukhuede et al., 2013; Chen et al., 2017), there is a need for increased protein-based, functional measurements.

qFlow cytometry offers a powerful tool for protein-based, single-cell measurements. It applies fluorescent calibration to traditional flow cytometry, converting signal to absolute protein concentrations (Lyer et al., 1997; Lee-Montiel and Imoukhuede, 2013; Chen et al., 2017). Absolute protein quantification allows detection of variations in proteins across published studies, tissues, replicates, and instrument settings (Wheeless et al., 1989; Rocha-Martins et al., 2012; Baumgartner et al., 2013; Nguyen et al., 2013; Vigelsø et al., 2015). Moreover, qFlow cytometry advances systems biology, providing the quantitative data needed for computational studies (Chen et al., 2014; Weddell and Imoukhuede, 2018). For example, using qFlow cytometry coupled with systems biology, we predicted that anti-VEGF efficacy depends on tumor endothelial VEGFR1 plasma membrane concentrations (Weddell and Imoukhuede, 2014). Furthermore, a receptor-internalization computational model recently predicted that small increases in plasma membrane RTK concentrations ( $<1,000$ receptors/cell) may double nuclear-based RTK signaling (Weddell and Imoukhuede, 2017), which further implicates RTK concentrations as a determinant of signal transduction. These predictions were only possible with the accurate experimental data offered by qFlow cytometry.

\section{A NEW APPROACH FOR EXAMINING GBM HETEROGENEITY}

We performed a "proof of concept" qFlow cytometry study on a PDX, GBM39 (Figure 1). GBM39 is known for EGFR ${ }^{\text {vII }}$ and low invasiveness, in vivo (Johnson et al., 2012; Wei et al., 2016). The xenograft was established with tumor tissue from patients undergoing surgical treatment at Mayo Clinic, Rochester, MN. Multiple studies characterize these PDX models and report maintenance of patient morphologic and molecular characteristics including EGFR amplification as well as tumor invasiveness (Giannini et al., 2005; Sarkaria et al., 2007).

Following dissociation, PDX cells were stained with Sytox Blue (a live/dead cell stain), CD45 (Patenaude et al., 2010), CD34 (Soares et al., 2007; Moghadam et al., 2015), and CD133 (Singh et al., 2004; Calabrese et al., 2007; Molina et al., 2014; Naujokat, 2014; Soeda et al., 2015) fluorophore-conjugated antibodies that target EC-like cells and GSCs, respectively (Figure 1). This labeling scheme excludes both dead cells and hematopoietic cells and enables identification of human tumor EC-like cells $\left(\mathrm{hCD}_{3} 4^{+}\right)$, mouse tumor EC-like cells $\left(\mathrm{mCD} 34^{+}\right)$, and GSCs $\left(\mathrm{hCD}_{133^{+}}\right.$) from the live $\mathrm{CD} 45^{-}$pool (Figure 2A). To obtain reliable data, we obtained fluorescence signals from 2 to 3 samples/RTK with 10,000-35,000 live single cells collected per sample. As expected, the bulk GBM39 PDX sample was primarily non-EC, non-GSC cells (62.46\%). In addition, we found 6-fold higher mouse tumor EC-like cells than human tumor EC-like cells (Figure 2B). This quantification aligned with prior studies of GBM xenograft showing $~ 7.1 \%$ EC population $\left(\mathrm{CD} 45^{-} \mathrm{CD} 31^{+} \mathrm{CD} 34^{+}\right)$. Consistent with our quantification of GSCs, a primary human study of 37 patients reported a range of $0.5-10 \%$ (Pallini et al., 2011), when identifying GSCs using the CD133 marker.

We labeled and screened 9 plasma membrane RTKs on these cells, which included two established GBM biomarkers, EGFR and insulin-like growth factor receptor (IGFR) (Sangar et al., 2014), and angiogenic signaling biomarkers: VEGFRs, PDGFRs, NRP1, and Tie2 (Carmeliet and Jain, 2000, 2011; Ferrara, 2002; Ferrara and Kerbel, 2005; Dudley, 2012). Using qFlow cytometry and statistical models, we quantitatively characterized GBM39 PDX via four patented metrics (Figure 1): cell composition, ensemble RTK concentration, cell-by-cell analysis with Gaussian mixture modeling, and heterogeneity analysis (Imoukhuede and Chen, 2018).

Percentage of gated cell populations were exported using FlowJo software (TreeStar). Ensemble RTK concentrations and cell-by-cell analysis were performed as previously described (Chen et al., 2015, 2017). We then applied Gaussian mixture modeling to identify log-normal sub-populations within each distribution, described by its mean, standard deviation, and density. We reduced the chance of overfitting the subpopulations by using Bayesian Information Criterion (BIC) (Raftery, 1995; Huedo-Medina et al., 2006). A detailed description of heterogeneity quantification is provided in section Quantification of Cell-RTK Heterogeneity.

\section{Human Tumor EC-Like Cells Have High EGFR and IGFR on Plasma Membrane}

EGFR and IGFR are expressed on tumor cells and contribute to tumor progression. Interestingly, the human tumor EClike population had high plasma membrane EGFR and IGFR concentrations ( $\sim 21,000 /$ cell and $\sim 20,000 /$ cell, respectively) (Figure 2C), consistent with qualitative findings of higher EGFR on breast carcinoma-derived ECs compared to normal ECs (Amin et al., 2006). Our results of high EGFR on human tumor 


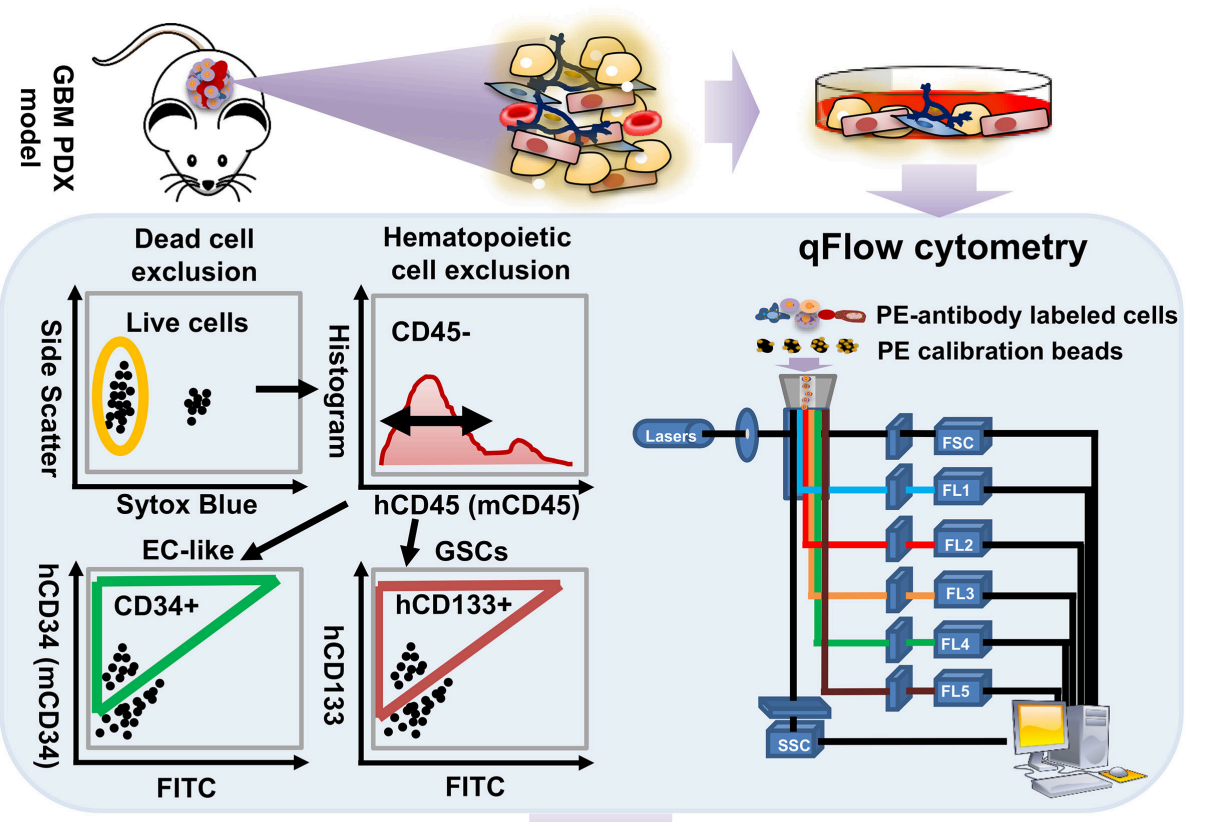

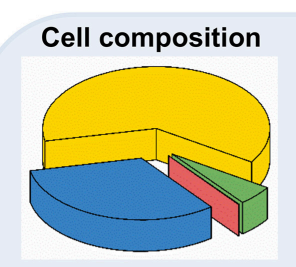

Cell-by-cell

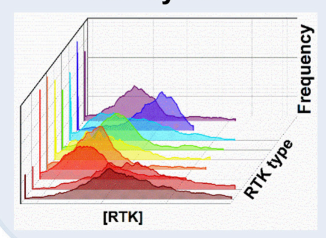

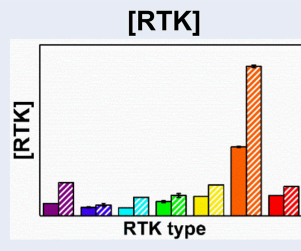

Heterogeneity

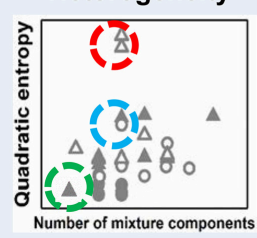

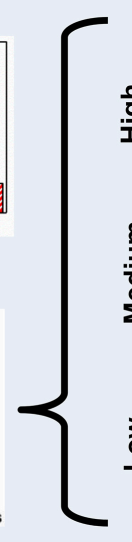

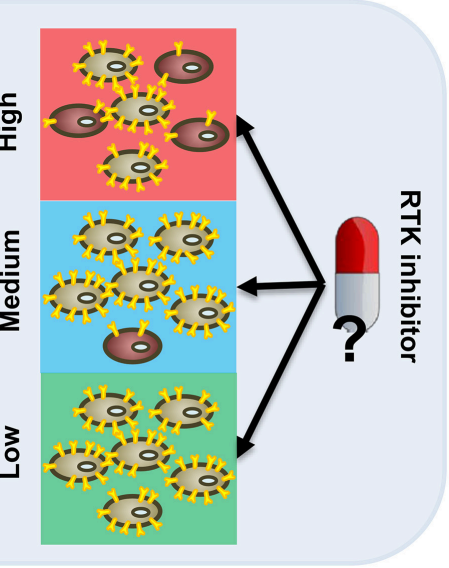

FIGURE 1 | An overview of the workflow for characterizing tumor heterogeneity in GBM39 PDX samples. The GBM39 PDX is established with tumor tissue from patients at Mayo Clinic, Rochester, MN. Following dissociation, multi-channel flow cytometer is used to characterize PDX cells. Briefly, dead cells are excluded using a live/dead cell stain, and hematopoietic cells are excluded using the CD45 antigen, then the endothelial marker CD34 and CD133 can be used to identify EC-like cells and GSCs respectively from the CD45- pool. Percentage of GSCs, EC-like cells and other PDX cells within all live cells can be exported from the flow cytometer. Cells are also stained with phycoerythrin (PE)-conjugated antibodies targeting one of the 9 plasma membrane RTKs: established GBM biomarkers, EGFR and IGFR, and those within the angiogenic signaling networks, VEGFRs, PDGFRs, NRP1, and Tie2. qFlow cytometry is performed as described previously, and ensemble averaged plasma membrane RTK concentrations and cell-by-cell RTK distributions can be obtained (Imoukhuede and Popel, 2011; Chen et al., 2015, 2017). We use two parameters to quantify RTK heterogeneity across EC-like and non EC-like cells: number of mixture components and Quadratic entropy of the cell-by-cell RTK distribution. Bayesian Information Criterion (BIC)-guided Gaussian mixture modeling is used to select the best number of mixture components existed in a larger cell population based on their RTK concentration. Alternatively, Quadratic entropy sums the weighted differences of the means between two bins from 500 equally distributed bins from each cell-by-cell distribution. We envision that characterizing RTK heterogeneity may help understand why RTK inhibitors have not been efficient in treating GBMs.

EC-like cells from GBM39 is also consistent with results of clinical GBM samples (Soda et al., 2011).

The mixture modeling revealed that $8 \%$ of human tumor EC-like subpopulations had a $\sim 12$-fold higher membrane localization of EGFRs than average. We found a similar pattern for IGFRs in human tumor EC-like subpopulations. Together, the ensemble-averaged data and the mixture modeling indicated significant plasma membrane localization of EGFR and IGFR on human tumor EC-like cells. High concentrations of EGFR and IGFR suggest an opportunity for targeted inhibition, which could be a mechanism for disrupting tumor vessels on GBMs with a similar profile. 

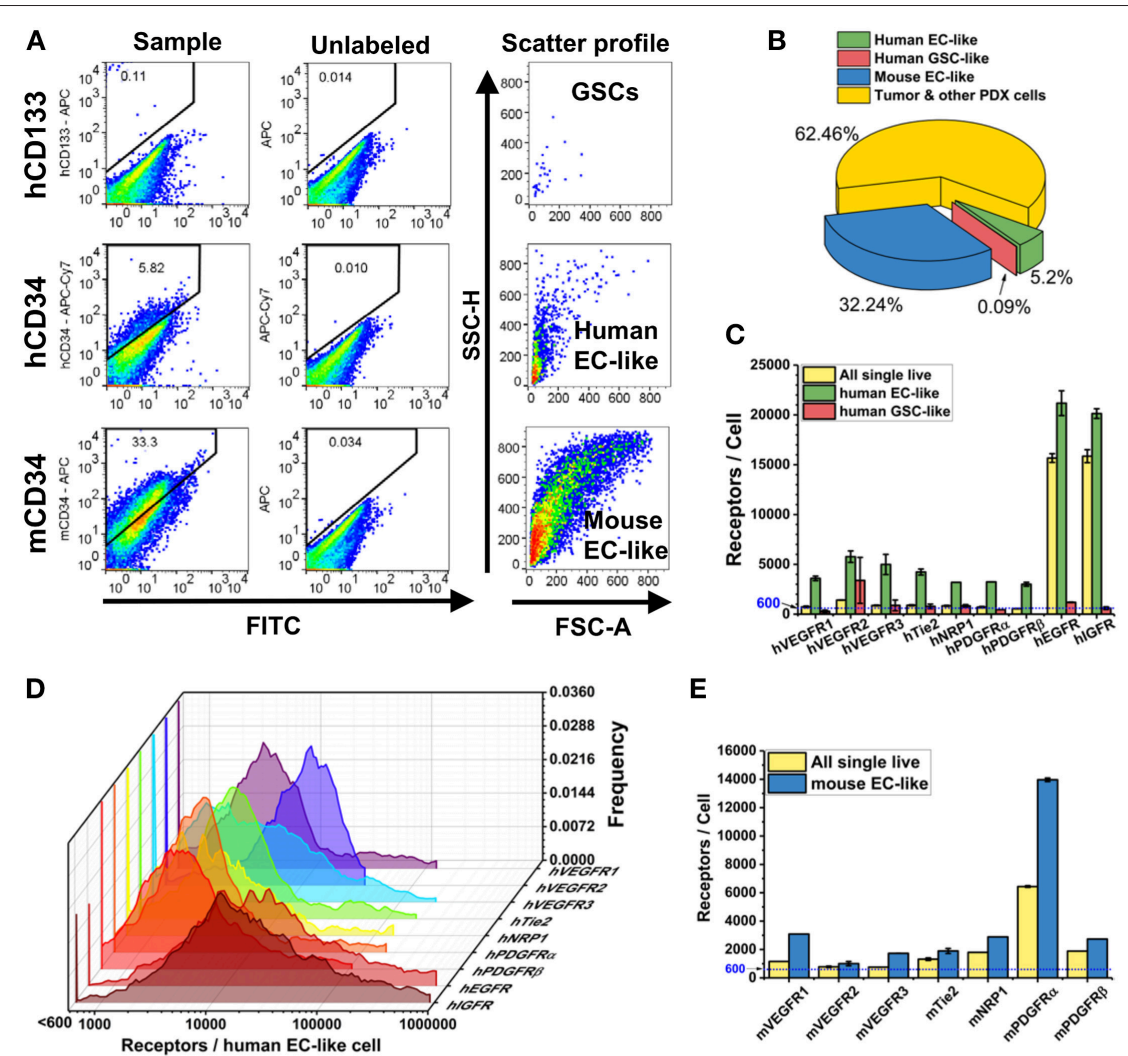

E
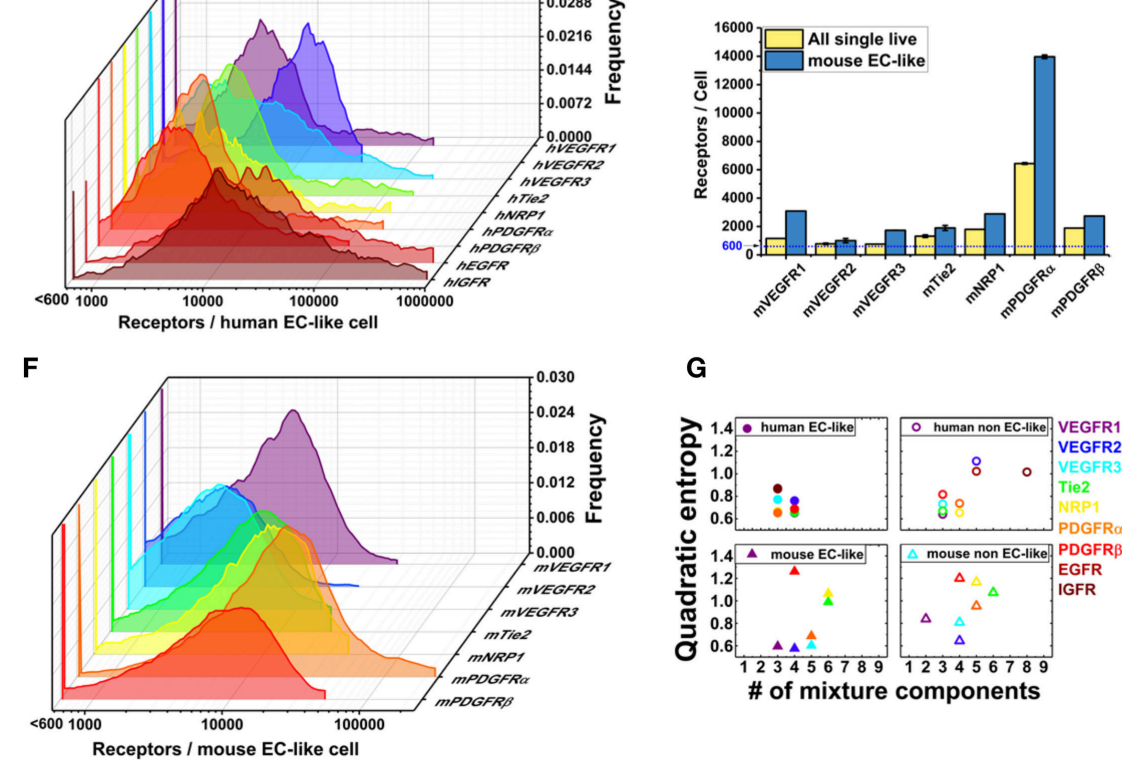

G

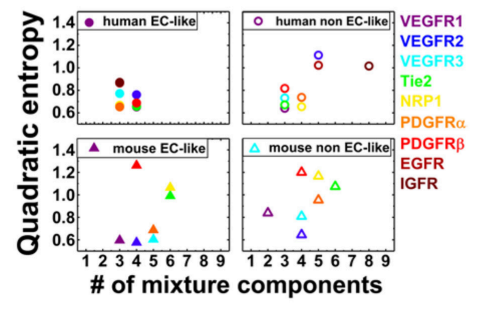

FIGURE 2 | Characterization of plasma membrane RTK concentrations and tumor heterogeneity in GBM39 PDX sample using a LSR Fortessa flow cytometer (BD). We obtain fluorescence signal from 2 to 3 sample tubes for each RTK with 10,000-35,000 live single cells per sample tube. BD FACSDIVA software was used for data acquisition, and FlowJo (TreeStar) software was used for data analysis. (A) Representative flow cytometry plots for gating GSCs (hCD45-hCD133+), human EC-like cells (hCD45-hCD34+), and mouse EC-like cells (mCD45-mCD34+) from live cell population. (B) Percentage of GSCs, human EC-like, mouse EC-like, and tumor \& other PDX cells in the GBM39 PDX sample. (C) Ensemble-averaged concentrations and (D) cell-by-cell distributions of plasma membrane VEGFRs, Tie2, NRP1, PDGFRs, EGFR, and IGFR on human EC-like cells. (E) Ensemble-averaged concentrations and (F) cell-by-cell distributions of plasma membrane VEGFRs, Tie2, NRP1, and PDGFRs on mouse EC-like cells. (G) Heterogeneity analysis of RTKs in EC-like and non EC-like cell populations. Number of mixture components estimates how many cell subpopulations there are having different plasma membrane RTK concentrations. Quadratic entropy represents the diversity of RTK concentrations within EC-like and non EC-like populations.

\section{Mouse Tumor EC-Like Cells Have Similar Plasma Membrane VEGFR Concentrations as Healthy Mouse ECs From Skeletal Muscle}

VEGFRs are key regulators of tumor angiogenesis, so their quantification can offer insight into the tumor vasculature. Furthermore, as biomarkers of vasculature, these receptors have been proposed as diagnostic biomarkers of anti-angiogenic drug efficacy (Lambrechts et al., 2013; Wehland et al., 2013) with computational (Weddell and Imoukhuede, 2014) and clinical (Weickhardt et al., 2015) support to their use. We found that VEGFR1 and VEGFR2 had similar concentrations and ratios on mouse tumor EC-like cells $(\sim 3,100$ VEGFR1/cell and $\sim 1,000$ VEGFR2/cell) as on healthy ECs obtained from mouse skeletal muscle (Imoukhuede and Popel, 2012) (Figure 2E). This finding of a low VEGFR2:VEGFR1 ratio aligns with a previous study on breast cancer xenografts (Imoukhuede and Popel, 2014); 
however, the receptor abundance we report here is much lower. These findings of EC-like cells from GBM39 having VEGFRs at levels similar to normal mouse skeletal muscle ECs suggests a need for further quantification of normal brain ECs VEGFR concentrations to establish tissue standards. Similarly, it suggests a need to examine other GBM specimens to identify whether this is a property of co-opted vessels or specific to this GBM strain.

We analyzed the human tumor EC-like population $(5.20 \%$ of the population, Figure 2B), which should reflect the original tumor vessels from the patient (Figure 2C). We found similar plasma membrane VEGFR1 and VEGFR2 ratios ( 3,600 VEGFR1/cell \& 5,800 VEGFR2/cell) as previous reports in vitro (Imoukhuede and Popel, 2011; Chen et al., 2015). However, these data show that not all tumors have the same concentrations or ratios of plasma membrane VEGFRs on their endothelium. Importantly, tumor EC-like cells display much greater heterogeneity than normal ECs with subpopulations that have high concentrations of VEGFRs. Indeed, cell-by-cell analysis and mixture modeling of human tumor EC-like cells reveals the existence of a high-VEGFR1 subpopulation $(\sim 10 \%)$ with $\sim 41,000$ VEGFR1/cell, while the highest VEGFR2 subpopulation is $\sim 18,500$ VEGFR2/cell, comprising $\sim 35 \%$ of the total human tumor EC-like population (Figures 2D,G). The difference in VEGFR2:VEGFR1 ratio and receptor concentrations between human and mouse tumor EC-like population shows a significant level of endothelial heterogeneity. Such data may enable correlations between these tumor vessel regulators and anti-angiogenic drug efficacy.

\section{Plasma Membrane PDGFRs Localize on Tumor EC-Like Cells}

PDGFRs serve important roles in supporting vasculature in tumor microenvironments (Andrae et al., 2008). We observed lower levels of PDGFRs on human tumor EC-like cell membranes than on mouse (Figures 2C,E). The cell-by-cell analysis and mixture modeling suggests that this ensemble average does not capture the subpopulations having high-PDGFR plasma membrane localization: 66 and $16 \%$ of mouse tumor EC-like cell membrane had $\sim 23,400$ PDGFR $\alpha$ and $\sim 19,800$ PDGFR $\beta$, respectively (Figure $2 \mathrm{~F}$ ). This significant heterogeneity may be attributed to the use of the CD34 marker to designate EC-like cells, because it is also found on stem cells/precursors, mast cells, and neurons (Nielsen and McNagny, 2008; Imoukhuede and Popel, 2014; AbuSamra et al., 2017). PDGFR $\alpha$ is also considered an important mesenchymal stem cell marker (Farahani and Xaymardan, 2015). So, the co-labeling of PDGFR $\alpha$ and CD34 suggests these cells may be mesenchymal stem cells (Aguirre et al., 2010).

If these $\mathrm{CD}_{3} 4^{+} \mathrm{PDGFR}^{+}$cells are endothelial, then our data correlates with studies finding PDGFRs on tumor ECs (Hermansson et al., 1988; Werner et al., 1990; Plate et al., 1992). PDGFR localization on ECs is controversial, because it is characteristic of mural cells and not of ECs (Heldin et al., 1981; Bowen-Pope and Ross, 1982; Kazlauskas and DiCorleto, 1985; Raines et al., 1991; Battegay et al., 1994; Marx et al., 1994). However, they have been observed on monolayer microvascular ECs, in vitro (Bar et al., 1989; Marx et al., 1994) and on angiogenic ECs that formed sprout and tubes in vitro (Battegay et al., 1994). If we subscribe to the canonical PDGFR localization understanding, then these tumor vessels induce "non-conventional" PDGFR localization patterns.

\section{GSCs Have Little-To-No Surface EGFR or IGFR}

Multiple studies suggest that a higher degree of GSC "stemness" is associated with EGFR amplification (Mazzoleni et al., 2010; Liffers et al., 2015); however, we observed $\sim 13$-fold lower EGFRs on GSC plasma membranes compared to the bulk PDX cells (Figure 2C). This trend was also seen with IGFR (Figure 2C). The low membrane EGFR concentrations on GSCs is concerning, given reports that EGFR signaling is necessary for GSC proliferation and tumor-sphere formation (Soeda et al., 2008; Griffero et al., 2009). Yet, this may explain the lower percentage of GSCs in the PDX sample $(\sim 0.9 \%)$ compared to the expected stem cell fraction (0.5-10\%; Pallini et al., 2011). A possible explanation is that serially transplanted tumors can lose their EGFR overexpression, even in vivo (Liffers et al., 2015). Clearly, further investigation of both gene expression and protein quantification on other GBM PDX GSCs is necessary to understand their contribution to heterogeneity and drugresistance.

\section{Quantification of Cell-RTK Heterogeneity}

To quantify heterogeneity of each cell subpopulation, we used two parameters: number of mixture components and Quadratic Entropy (QE). To quantitatively assess the number of subpopulations within each cell population, we fit each cellby-cell RTK distribution with mixture models consisting of 19 log-normal Gaussian sub-distributions (mixture components); we then applied BIC as the criterion to select the mixture model with the lowest BIC. The number of mixture components is determined by how many log-normal Gaussian sub-distributions are in the mixture model. The number of mixture components, thus, is a measurement of cell heterogeneity. Generally, 1-2 mixture components are considered low heterogeneity (Chen et al., 2017), while more than two components is considered highly heterogeneous (Imoukhuede and Popel, 2014; Weddell and Imoukhuede, 2014).

Alternatively, QE requires equally spaced bins, here we chose 500 bins, from each cell-by-cell distribution (Figures 2D,F). QE then sums the weighted differences of the means between two bins (Rao, 1982; Pavoine and Dolédec, 2005; Zoltán, 2005). Thus, $\mathrm{QE}$ is a measurement of the increase in random variation in the cellular response. Because healthy ECs and human fibroblasts in vitro have shown QE within 0.2-0.7 (Chen et al., 2015), we describe $\mathrm{QE}<0.7$ as low heterogeneity and $\mathrm{QE}>0.7$ as high heterogeneity. $\mathrm{QE}$ provides a quantitative measure of the diversity of cellular phenotypes in cancer tissue sections for diagnostic applications (Potts et al., 2012) and drug discovery (Gough et al., 2014). Interestingly, human tumor EC-like cells showed lower QE and number of mixture components when compared to mouse tumor EC-like cells (Figure 2G). We suspect that the likely loss of human tumor-associated cells over time in 
a PDX model (Chao et al., 2017) may be the reason why human tumor EC-like cells present a more homogenous state than the mouse tumor EC-like cells.

\section{Clinical Implications of GBM Heterogeneity}

We envision that RTK quantification can identify ideal receptor targets across the bulk tumor specimen and on specific cell populations in the tumor. First, the ideal receptor target would be highly available (Rich and Bigner, 2004; Weis and Cheresh, 2011; Cloughesy et al., 2014): it would have high concentrations on a high percentage of bulk cells or specific cells. Next, the target RTK would exhibit low heterogeneity: it would have low QE in bulk cells or on the specific cell subpopulation (Jain et al., 2009; Heath et al., 2016). An ideal receptor target would also be highly specific to the tumor, which would manifest as higher receptor concentrations in the tumor vs. healthy tissue (Rich and Bigner, 2004).

Based on these guidelines, we offer possible targets on GBM39. If the goal is targeting tumor vessels, then VEGFR2 and PDGFR $\alpha$ are highly targetable: $>70 \%$ target cells have $>6,000$ VEGFR2 or PDGFR $\alpha /$ cell plasma membrane with $\mathrm{QE}=0.20$ or 0.32 , respectively. Furthermore, they are likely targets, because they are more highly expressed in GBM specimens than health tissue (Chen et al., 2015): $\sim 5$-fold higher VEGFR2 and $\sim 4$-fold higher PDGFR $\alpha$. Therefore, targeting VEGFR2 and PDGFR $\alpha$ should preferentially target the tumor.

Our work suggests that targeting EGFR and IGFR on tumors like GBM39 may not be effective by itself. Although, they have high concentrations on $\sim 70-90 \%$ EC-like and non-EClike GBM cells, their high GBM heterogeneity $(\mathrm{QE}=\sim 1.0)$ and high concentration on healthy tissue $\left(2-2,000 \times 10^{3}\right.$ EGFR/fibroblast or epithelial cell; $2.5 \times 10^{4}$ IGFR/NIH 3T3 mouse fibroblasts (Sorkin and Duex, 2010; Brennan et al., 2013; Weddell and Imoukhuede, 2017) may lower their targeting specificity, resulting in lower drug efficacy (Wheeler et al., 2010). Better drug delivery to the tumor site will likely improve targeting specificity without disrupting healthy tissue. An alternative strategy is to develop dual-inhibitors targeting both EGFR/IGFR and VEGFR2 to increase their specificity for tumor EC-like cells.

We believe our method can also identify cellular and molecular mechanisms underlying reduced response to drugs. For example, upregulation of alternative signaling pathways has been implicated in anti-VEGF drug resistance (Bergers and Hanahan, 2008; Shojaei and Ferrara, 2008). This mechanism of drug resistance is often accompanied by significant tumor heterogeneity (Snuderl et al., 2011; Szerlip et al., 2012; Lu and Bergers, 2013). Therefore, these alternative pathways may be overlooked in bulk studies if they are only present on small cell subpopulations. From this study, we suggest targeting RTKs that are localized on plasma membrane at high concentrations on small cell populations $(<10 \%)$ for combination therapy. For example, VEGFR1 and Tie2 on tumor ECs may become "alternative" RTKs for anti-VEGF treatment, because we found $\sim 10 \%$ human tumor EC-like cell subpopulations had 41,000 VEGFR1 and $\sim 8 \%$ had 65,700 Tie2 on the plasma membrane. Identifying alternative RTK pathways that contribute to resistance can provide tumor-specific drug targets for combination therapy.

\section{FUTURE DIRECTION IN CHARACTERIZING GBM HETEROGENEITY}

Our study of the GBM39 PDX model, arrived at 4 key findings and 2 recommendations: (1) tumor EC-like subpopulations have high concentrations of plasma membrane VEGFR1 and VEGFR2; (2) human vs. mouse tumor EC-like cells have inverted VEGFR2:VEGFR1 ratios; (3) tumor EC-like subpopulations have high plasma membrane EGFR, IGFR, and PDGFR concentrations; and (4) GSCs compose a low percentage of cells in the tumor and have little-to-no EGFRs and IGFRs on their plasma membranes.

Based on findings in this study and our RTK-targeting criteria, VEGFR2 or PDGFR $\alpha$ would be likely drug targets for GBM39. In addition, VEGFR1 and Tie 2 are likely drug targets for combination therapy. The next step would be to test these targets in a GBM PDX model.

The results of this "proof of concept" study should be interpreted as such: it offers an approach for continued measurement of tumor samples, broadly, and GBM samples, specifically, with the GBM39 PDX sample as a first example. We present the novel method, qFlow cytometry, and show its application in characterizing GBM heterogeneity. Larger and well-powered samples are warranted to expand the current preliminary results, and to discover ideal drug targets and mechanisms underlying drug resistance.

Future opportunities for expanding this research lies in establishing protein concentration ranges on additional samples and continued development of biomimetic tumor models. Firstly, additional measurements of protein concentration on normal ECs and other cells would provide the baselines needed to compare to tumor. In establishing EC baselines, isolation of a pure EC population may be a challenge. Previous qFlow studies have identified ECs using both the CD34 and CD31 markers (Imoukhuede and Popel, 2012, 2014; Imoukhuede et al., 2013). However, it is important to note, that using multiple markers can bias cell collection: $\mathrm{CD} 34$ is a progenitor marker, so its use biases selection from more mature cells. Whereas, CD31 is a mature cell marker that is found on ECs, platelets, natural killer cells, monocytes, macrophages, and among other cells (Liu and Shi, 2012), so its use can lead to sample impurity. Here, we chose to bias toward progenitor-like ECs; however, expanded studies may determine if protein concentrations correlate with marker presentation (e.g., identifying whether progenitor-like cells having higher or lower protein concentrations).

Another opportunity for advancement lies in our quantitative single-cell RTK mapping, moving toward multiplexed measurement of RTKs. Toward multiplexed quantification, Lee-Montiel et al., developed a quantum dot method for receptor labeling and calibration (Lee-Montiel and Imoukhuede, 2013; Lee-Montiel et al., 2015) that can be translated to qFlow cytometry. Another approach could be to adapt receptor quantification to mass cytometry (CyTOF) (Spitzer and Nolan, 
2016). Such advancements would provide multi-RTK, multi-cell insight into tumor heterogeneity.

In conclusion, cancer research is experiencing a paradigm shift from ensemble analysis to cell-to-cell variability (Niepel et al., 2009; Hoppe et al., 2014; Dar and Weiss, 2018) because of the increasing evidence correlating drug resistance with tumor heterogeneity. The perspective and work that we present here offers sensitive methods for heterogeneity characterization in tumors that should enable improved treatment. We believe that continued quantification of single-cell receptor heterogeneity is a new frontier that will offer significant clinical impact.

\section{AUTHOR CONTRIBUTIONS}

SC and PI designed the study. $\mathrm{BH}$ provided samples and contributed critical insight into GBM and discussion on the studies. SC performed the experiments and quantified RTK

\section{REFERENCES}

AbuSamra, D. B., Fajr, A. A., Asma, S. A., Heba, M. J. A., Chee, J. C., Ayman, F. A., et al. (2017). Not just a marker: $c d 34$ on human hematopoietic stem/progenitor cells dominates vascular selectin binding along with CD44. Blood Adv. 1, 2799-2816. doi: 10.1182/bloodadvances.2017004317

Aguirre, A., Planell, J. A., and Engel, E. (2010). Dynamics of bone marrow-derived endothelial progenitor cell/mesenchymal stem cell interaction in co-culture and its implications in angiogenesis. Biochem. Biophys. Res, Commun. 400, 284-291. doi: 10.1016/j.bbrc.2010.08.073

Aird, W. C. (2009). Molecular heterogeneity of tumor endothelium. Cell Tissue Res. 335, 271-281. doi: 10.1007/s00441-008-0672-y

Amin, D. N., Hida, K., Bielenberg, D. R., and Klagsbrun, M. (2006). Tumor endothelial cells express epidermal growth factor receptor (EGFR) but not ErbB3 and are responsive to EGF and to EGFR |. Cancer Res. 66, 2173-2180. doi: 10.1158/0008-5472.CAN-05-3387

Andrae, J., Gallini, R., and Betsholtz, C. (2008). Role of platelet-derived growth factors in physiology and medicine. Genes Dev. 22, 1276-1312. doi: $10.1101 / \mathrm{gad} .1653708$

Ball, S. G., Shuttleworth, C. A., and Kielty, C. M. (2007). Vascular endothelial growth factor can signal through platelet-derived growth factor receptors. $J$. Cell Biol. 177, 489-500. doi: 10.1083/jcb.200608093

Bar, R. S., Boes, M., Booth, B. A., Dake, B. L., Henley, S., and Hart, M. N. (1989). The effects of platelet-derived growth factor in cultured microvessel endothelial cells. Endocrinology 124, 1841-1848. doi: 10.1210/endo-124-4-1841

Battegay, E. J., Rupp, J., Iruela-Arispe, L., Sage, E. H., and Pech, M. (1994). PDGF$\mathrm{BB}$ modulates endothelial proliferation and angiogenesis in vitro via PDGF beta-receptors. J. Cell Biol. 125, 917-928. doi: 10.1083/jcb.125.4.917

Baumgartner, R., Umlauf, E., Veitinger, M., Guterres, S., Rappold, E., Babeluk, R., et al. (2013). Identification and validation of platelet low biological variation proteins, superior to GAPDH, actin and tubulin, as tools in clinical proteomics. J. Proteomics 94, 540-551. doi: 10.1016/j.jprot.2013.10.015

Beier, D., Hau, P., Proescholdt, M., Lohmeier, A., Wischhusen, J., Oefner, P. J., et al. (2007). CD133(+) and CD133(-) glioblastoma-derived cancer stem cells show differential growth characteristics and molecular profiles. Cancer Res. 67, 4010-4015. doi: 10.1158/0008-5472.CAN-06-4180

Bergers, G., and Hanahan, D. (2008). Modes of resistance to anti-angiogenic therapy. Nat. Rev. Cancer 8, 592-603. doi: 10.1038/nrc2442

Bowen-Pope, D. F., and Ross, R. (1982). Platelet-derived growth factor. II. Specific binding to cultured cells. J. Biol. Chem. 257, 5161-5171.

Bradshaw, A., Wickremsekera, A., Tan, S. T., Peng, L., Davis, P. F., and Itinteang, T. (2016). Cancer stem cell hierarchy in glioblastoma multiforme. Front. Surg. 3:21. doi: 10.3389/fsurg.2016.00021 plasma membrane concentrations. SC, TL, and PI conducted and discussed data analysis. SC, TL, and PI prepared the manuscript.

\section{ACKNOWLEDGMENTS}

This work was supported by grants from the National Science Foundation (1512598 and 1653925), and the American Heart Association (16SDG26940002). Research reported in this publication was also supported by the National Cancer Institute of the National Institutes of Health under Award Number R01 CA197488 (BACH). The content is solely the responsibility of the authors and does not necessarily represent the official views of the NIH. We would like to thank members of BH's lab, Dr. Sara Pedron and Jee-Wei Emily Chen at University of Illinois at Urbana-Champaign, and Dr. Jann Sarkaria at Mayo Clinic (Rochester, MN) for the generous supply of GBM PDX samples.
Brennan, C. W., Verhaak, R. G. W., McKenna, A., Campos, B., Noushmehr, H., Salama, S. R., Zheng, S., et al. (2013). The somatic genomic landscape of glioblastoma. Cell 155, 462-477. doi: 10.1016/j.cell.2013.09.034

Brennan, C., Momota, H., Hambardzumyan, D., Ozawa, T., Tandon, A., Pedraza, A., et al. (2009). Glioblastoma subclasses can be defined by activity among signal transduction pathways and associated genomic alterations. PLoS ONE 4:e7752. doi: 10.1371/journal.pone.0007752

Cadena, D. L., and Gill, G. N. (1992). Receptor tyrosine kinases. FASEB J. 6, 2332-2337. doi: 10.1096/fasebj.6.6.1312047

Calabrese, C., Poppleton, H., Kocak, M., Hogg, T. L., Fuller, C., Hamner, B., Oh, E. Y., et al. (2007). A perivascular niche for brain tumor stem cells. Cancer Cell 11, 69-82. doi: 10.1016/j.ccr.2006.11.020

Candolfi, M., Kroeger, K. M., Xiong, W., Liu, C., Puntel, M., Yagiz, K., Muhammad, A. G., et al. (2011). Targeted toxins for glioblastoma multiforme: pre-clinical studies and clinical implementation. Anticancer. Agents Med. Chem. 11, 729-738. doi: 10.2174/187152011797378689

Carmeliet, P., and Jain, R. K. (2000). Angiogenesis in cancer and other diseases. J. Nat. 407, 249-257. doi: 10.1038/35025220

Carmeliet, P., and Jain, R. K. (2011). Molecular mechanisms and clinical applications of angiogenesis. Nature 473, 298-307. doi: 10.1038/nature10144

Chao, C., Widen, S. G., Wood, T. G., Zatarain, J. R., Johnson, P., Gajjar, A., Gomez, G., et al. (2017). Patient-derived xenografts from colorectal carcinoma: a temporal and hierarchical study of murine stromal cell replacement. Anticancer Res. 37, 3405-3412. doi: 10.21873/anticanres.11707

Chen, S., Ansari, A., Sterrett, W., Hurley, K., Kemball, J., Weddell, J. C., et al. (2014). Current state-of-the-art and future directions in systems biology. Progr. Commun. Sci. 1, 12-26.

Chen, S., Guo, X., Imarenezor, O., and Imoukhuede, P. I. (2015). Quantification of VEGFRs, NRP1, and PDGFRs on endothelial cells and fibroblasts reveals serum, intra-family ligand, and cross-family ligand regulation. Cell. Mol. Bioeng. 8, 383-403. doi: 10.1007/s12195-015-0411-x

Chen, S., Weddell, J. C., Gupta, P., Conard, G., Parkin, J., and Imoukhuede, P. I. (2017). qFlow cytometry-based receptoromic screening: a highthroughput quantification approach informing biomarker selection and nanosensor development. Methods Mol. Biol. 1570, 117-138. doi: 10.1007/978-1-4939-6840-4_8

Chung, I., Akita, R., Vandlen, R., Toomre, D., Schlessinger, J., and Mellman, I. (2010). Spatial control of EGF receptor activation by reversible dimerization on living cells. Nature 464, 783-787. doi: 10.1038/nature 08827

Cloughesy, T. F., Cavenee, W. K., and Mischel, P. S. (2014). Glioblastoma: from molecular pathology to targeted treatment. Ann. Rev. Pathol. Mech. Dis. 9, 1-25. doi: 10.1146/annurev-pathol-011110-130324 
Comps-Agrar, L., Dunshee, D. R., Eaton, D. L., and Sonoda, J. (2015). Unliganded fibroblast growth factor receptor 1 forms density-independent dimers. J. Biol. Chem. 290, 24166-24177. doi: 10.1074/jbc.M115.681395

Dar, R. D., and Weiss, R. (2018). Perspective: engineering noise in biological systems towards predictive stochastic design. APL Bioeng. 2:020901. doi: $10.1063 / 1.5025033$

De Witt Hamer, P. C. (2010). Small molecule kinase inhibitors in glioblastoma: a systematic review of clinical studies. Neurooncology 12, 304-316. doi: 10.1093/neuonc/nop068

Dudley, A. C. (2012). Tumor endothelial cells. Cold Spring Harb. Perspect. Med. 2:a006536. doi: 10.1101/cshperspect.a006536

Dunn, G. P., Rinne, M. L., Wykosky, J., Genovese, G., Quayle, S. N., Dunn, I. F., Agarwalla, P. K., et al. (2012). Emerging insights into the molecular and cellular basis of glioblastoma. Genes Dev. 26, 756-784. doi: 10.1101/gad.187922.112

Ellis, H. P., Greenslade, M., Powell, B., Spiteri, I., Sottoriva, A., and Kurian, K. M. (2015). Current challenges in glioblastoma: intratumour heterogeneity, residual disease, and models to predict disease recurrence. Front. Oncol. 5:251. doi: $10.3389 /$ fonc. 2015.00251

Farahani, R. M., and Xaymardan, M. (2015). Platelet-derived growth factor receptor alpha as a marker of mesenchymal stem cells in development and stem cell biology. Stem Cells Int. 2015:362753. doi: 10.1155/2015/362753

Feng, Y., Mitchison, T. J., Bender, A., Young, D. W., and Tallarico, J. A. (2009). Multi-parameter phenotypic profiling: using cellular effects to characterize small-molecule compounds. Nat. Rev. Drug Discov. 8, 567-578. doi: $10.1038 / \mathrm{nrd} 2876$

Ferrara, N. (2002). VEGF and the quest for tumour angiogenesis factors. Nat. Rev. Cancer 2, 795-803. doi: 10.1038/nrc909

Ferrara, N., and Kerbel, R. S. (2005). Angiogenesis as a therapeutic target. Nature 438, 967-974. doi: 10.1038/nature04483

Ferrara, N., Gerber, H., and LeCouter, J. (2003). The biology of VEGF and its receptors. Nat. Med. 9, 669-676. doi: 10.1038/nm0603-669

Furnari, F. B., Cloughesy, T. F., Cavenee, W. K., and Mischel, P. S. (2015). Heterogeneity of epidermal growth factor receptor signalling networks in glioblastoma. Nat. Rev. Cancer 15, 302-310. doi: 10.1038/nrc3918

Gelfand, M. V., Hagan, N., Tata, A., Oh, W., Lacoste, B., Kang, K., et al. (2014). Neuropilin-1 functions as a VEGFR2 co-receptor to guide developmental angiogenesis independent of ligand binding. ELife 3:e03720. doi: 10.7554/eLife.03720

Giannini, C., Sarkaria, J. N., Saito, A., Uhm, J. H., Galanis, E., Carlson, B. L., et al. (2005). Patient tumor EGFR and PDGFRA gene amplifications retained in an invasive intracranial xenograft model of glioblastoma multiforme. Neurooncology 7, 164-176. doi: 10.1215/S1152851704000821

Golebiewska, A., Bougnaud, S., Stieber, D., Brons, N. H. C., Vallar, L., Hertel, F., et al. (2013). Side population in human glioblastoma is non-tumorigenic and characterizes brain endothelial cells. Brain 136 (Pt 5), 1462-1475. doi: 10.1093/brain/awt025

Gough, A. H., Chen, N., Shun, T. Y., Lezon, T. R., Boltz, R. C., Reese, C. E., Wagner, J., et al. (2014). Identifying and quantifying heterogeneity in high content analysis: application of heterogeneity indices to drug discovery. PLoS ONE 9:e102678. doi: 10.1371/journal.pone.0102678

Greaves, M. (2015). Evolutionary determinants of cancer. Cancer Discov. 5, 806-820. doi: 10.1158/2159-8290.CD-15-0439

Greaves, M., and Maley, C. C. (2012). Clonal evolution in cancer. Nature 481, 306-313. doi: 10.1038/nature10762

Grecco, H. E., Schmick, M., and Bastiaens, P. I. H. (2011). Signaling from the living plasma membrane. Cell 144, 897-909. doi: 10.1016/j.cell.2011.01.029

Greenberg, J. I., Shields, D. J., Barillas, S. G., Acevedo, L. M., Murphy, E., Huang, J., Scheppke, L., et al. (2008). A Role for VEGF as a negative regulator of pericyte function and vessel maturation. Nature 456, 809-813. doi: 10.1038/nature07424

Griffero, F., Daga, A., Marubbi, D., Capra, M. C., Melotti, A., Pattarozzi, A., Gatti, M., et al. (2009). Different response of human glioma tumor-initiating cells to epidermal growth factor receptor kinase inhibitors. J. Biol. Chem. 284, 7138-7148. doi: 10.1074/jbc.M807111200

Hanahan, D., and Weinberg, R. A. (2011). Hallmarks of cancer: the next generation. Cell 144, 646-674. doi: 10.1016/j.cell.2011.02.013

Hawkins-Daarud, A., Rockne, R. C., Anderson, A. R. A., and Swanson, K. R. (2013). Modeling tumor-associated edema in gliomas during anti-angiogenic therapy and its impact on imageable tumor. Front. Oncol. 3:66 doi: $10.3389 /$ fonc. 2013.00066

Heath, J. R., Ribas, A., and Mischel, P. S. (2016). Single-cell analysis tools for drug discovery and development. Nat. Rev. Drug Discov. 15, 204-216. doi: $10.1038 / \mathrm{nrd} .2015 .16$

Heldin, C. H., Westermark, B., and Wasteson, A. (1981). Specific receptors for platelet-derived growth factor on cells derived from connective tissue and glia. Proc. Natl. Acad. Sci. U.S.A. 78, 3664-3668. doi: 10.1073/pnas.78.6.3664

Hermanson, M., Funa, K., Hartman, M., Claesson-Welsh, L., Heldin, C. H., Westermark, B., et al. (1992). Platelet-derived growth factor and its receptors in human glioma tissue: expression of messenger RNA and protein suggests the presence of autocrine and paracrine loops. Cancer Res. 52, 3213-3219.

Hermansson, M., Nistér, M., Betsholtz, C., Heldin, C. H., Westermark, B., and Funa, K. (1988). Endothelial cell hyperplasia in human glioblastoma: coexpression of mRNA for platelet-derived growth factor (PDGF) B chain and PDGF receptor suggests autocrine growth stimulation. Proc. Natl. Acad. Sci. U.S.A. 85, 7748-7752. doi: 10.1073/pnas.85.20.7748

Holash, J., Maisonpierre, P. C., Compton, D., Boland, P., Alexander, C. R., Zagzag, D., et al. (1999). Vessel cooption, regression, and growth in tumors mediated by angiopoietins and VEGF. Science 284, 1994-1998. doi: 10.1126/science.284.5422.1994

Hoppe, P. S., Coutu, D. L., and Schroeder, T. (2014). Single-cell technologies sharpen up mammalian stem cell research. Nat. Cell Biol. 16, 919-927. doi: $10.1038 /$ ncb3042

Hubbard, S. R., and Miller, W. T. (2007). Receptor tyrosine kinases: mechanisms of activation and signaling. Curr. Opin. Cell Biol. 19, 117-123. doi: 10.1016/j.ceb.2007.02.010

Huedo-Medina, T. B., Sánchez-Meca, J., Marín-Martínez, F., and Botella, J. (2006). Assessing heterogeneity in meta-analysis: Q statistic or $\mathrm{I}^{2}$ index? Psychol. Methods 11, 193-206. doi: 10.1037/1082-989X.11.2.193

Imoukhuede, P. I., and Chen, S. (2018). Characterizing Heterogeneity via SingleCell Receptor Quantification. UIUC2018-032-01(PRO).

Imoukhuede, P. I., and Popel, A. S. (2011). Quantification and cell-to-cell variation of vascular endothelial growth factor receptors. Exp. Cell Res. 317, 955-965. doi: 10.1016/j.yexcr.2010.12.014

Imoukhuede, P. I., and Popel, A. S. (2012). Expression of VEGF receptors on endothelial cells in mouse skeletal muscle. PLoS ONE 7:e44791. doi: 10.1371/journal.pone.0044791

Imoukhuede, P. I., and Popel, A. S. (2014). Quantitative fluorescent profiling of VEGFRs reveals tumor cell and endothelial cell heterogeneity in breast cancer xenografts. Cancer Med. 3, 225-244. doi: 10.1002/cam4.188

Imoukhuede, P. I., Dokun, A. O., Annex, B. H., and Popel, A. S. (2013). Endothelial cell-by-cell profiling reveals the temporal dynamics of VEGFR1 and VEGFR2 membrane localization after murine hindlimb ischemia. Am. J. Physiol. Heart Circ. Physiol. 304, H1085-H1093. doi: 10.1152/ajpheart.005 14.2012

Jain, R. K. (2005). Normalization of tumor vasculature: an emerging concept in antiangiogenic therapy. Science 307, 58-62. doi: 10.1126/science.1104819

Jain, R. K., Duda, D. G., Willett, C. G., Sahani, D. V., Zhu, A. X., Loeffler, J. S., et al. (2009). Biomarkers of response and resistance to antiangiogenic therapy. Nat. Rev. Clin. Oncol. 6, 327-338. doi: 10.1038/nrclinonc.2009.63

Jain, R. K., Tomaso, E. D., Duda, D. G., Loeffler, J. S., Sorensen, A. G., and Batchelor, T. T. (2007). Angiogenesis in brain tumours. Nat. Rev. Neurosci. 8, 610-622. doi: $10.1038 / \mathrm{nrn} 2175$

Jayson, G. C., Kerbel, R., Ellis, L. M., and Harris, A. L. (2016). Antiangiogenic therapy in oncology: current status and future directions. Lancet 388, 518-529. doi: 10.1016/S0140-6736(15)01088-0

Johnson, H., Rosario, A. M. D., Bryson, B. D., Schroeder, M. A., Sarkaria, J. N., and White, F. M. (2012). Molecular characterization of EGFR and EGFRvIII signaling networks in human glioblastoma tumor xenografts. Mol. Cell. Proteomics 11, 1724-1740. doi: 10.1074/mcp.M112.019984

Kazlauskas, A. (2017). PDGFs and their receptors. Gene 614, 1-7. doi: 10.1016/j.gene.2017.03.003

Kazlauskas, A., and DiCorleto, P. E. (1985). Cultured endothelial cells do not respond to a platelet-derived growth-factor-like protein in an autocrine manner. Biochim. Biophys. Acta 846, 405-412. doi: $10.1016 / 0167-4889(85) 90013-8$ 
King, C., Stoneman, M., Raicu, V., and Hristova, K. (2016). Fully quantified spectral imaging reveals in vivo membrane protein interactions. Integr. Biol. 8, 216-229. doi: 10.1039/C5IB00202H

Kuczynski, E. A., Patten, S. G., and Coomber, B. L. (2011). VEGFR2 expression and TGF- $\beta$ signaling in initial and recurrent high-grade human glioma. Oncology 81, 126-134. doi: 10.1159/000332849

Kuczynski, E. A., Yin, M., Bar-Zion, A., Lee, C. R., Butz, H., Man, S., Daley, F., et al. (2016). Co-option of liver vessels and not sprouting angiogenesis drives acquired sorafenib resistance in hepatocellular carcinoma. J. Natl. Cancer Inst. 108:djw030. doi: 10.1093/jnci/djw030

Kut, C., Gabhann, F. M., and Popel, A. S. (2007). Where is VEGF in the body? A meta-analysis of VEGF distribution in cancer. Brit. J. Cancer 97, 978-985. doi: $10.1038 /$ sj.bjc.6603923

Lambrechts, D., Lenz, H., Haas, S., Carmeliet, P., and Scherer, S. J. (2013). Markers of response for the antiangiogenic agent bevacizumab. J. Clin. Oncol. 31, 1219-1230. doi: 10.1200/JCO.2012.46.2762

Lathia, J. D., Mack, S. C., Mulkearns-Hubert, E. E., Valentim, C. L. L., and Rich, J. N. (2015). Cancer stem cells in glioblastoma. Genes Dev. 29, 1203-1217. doi: $10.1101 / \operatorname{gad} .261982 .115$

Lee-Montiel, F. T., and Imoukhuede, P. I. (2013). Engineering quantum dot calibration standards for quantitative fluorescent profiling. J. Mater. Chem. B 1, 6434. doi: 10.1039/c3tb20904k

Lee-Montiel, F. T., Li, P., and Imoukhuede, P. I. (2015). Quantum dot multiplexing for the profiling of cellular receptors. Nanoscale 7, 18504-18514. doi: 10.1039/C5NR01455G

Liffers, K., Lamszus, K., and Schulte, A. (2015). EGFR amplification and glioblastoma stem-like cells. Stem Cells Int. 2015:427518. doi: $10.1155 / 2015 / 427518$

Lin, C. C., Melo, F. A., Ghosh, R., Suen, K. M., Stagg, L. J., Kirkpatrick, J., et al. (2012). Inhibition of basal FGF receptor signaling by dimeric Grb2. Cell 149, 1514-1524. doi: 10.1016/j.cell.2012.04.033

Liu, L., and Shi, G. P. (2012). CD31: beyond a marker for endothelial cells. Cardiovasc. Res. 94, 3-5. doi: 10.1093/cvr/cvs108

Low-Nam, S. T., Lidke, K. A., Cutler, P. J., Roovers, R. C., Henegouwen, P. M. B. P., Wilson, B. S., et al. (2011). ErbB1 dimerization is promoted by domain co-confinement and stabilized by ligand binding. Nat. Struct. Mol. Biol. 18, 1244-1249. doi: 10.1038/nsmb.2135

Lu, K. V., and Bergers, G. (2013). Mechanisms of evasive resistance to anti-VEGF therapy in glioblastoma. CNS Oncol. 2, 49-65. doi: 10.2217/cns.12.36

Lyer, S., Bishop, J., Abrams, B., Maino, V., Ward, A., Christian, T., et al. (1997). QuantiBRITE: A New Standard for PE Flourescence Quantitation. San Jose, CA: Becton Dickinson Immunocytometry Systems.

Mac Gabhann, F., and Popel, A. S. (2007). Dimerization of VEGF receptors and implications for signal transduction: a computational study. Biophys. Chem. 128, 125-139. doi: 10.1016/j.bpc.2007.03.010

Mac Gabhann, F. and Popel, A. S. (2008). Systems biology of vascular endothelial growth factors. Microcirculation. 15, 715-738. doi: 10.1080/107396808020 95964

Mak, A. B., Blakely, K. M., Williams, R. A., Penttilä, P., Shukalyuk, A. I., Osman, K. T., et al. (2011). CD133 protein $N$-glycosylation processing contributes to cell surface recognition of the primitive cell marker AC133 epitope. J. Biol. Chem. 286, 41046-41056. doi: 10.1074/jbc.M111.261545

Mamer, S. B., Chen, S., Weddell, J. C., Palasz, A., Wittenkeller, A., Kumar, M., et al. (2017). Discovery of high-affinity PDGF-VEGFR interactions: redefining RTK dynamics. Sci. Rep. 7:16439. doi: 10.1038/s41598-017-16610-z

Marx, M., Perlmutter, R. A., and Madri, J. A. (1994). Modulation of plateletderived growth factor receptor expression in microvascular endothelial cells during in vitro angiogenesis. J. Clin. Invest. 93, 131-139. doi: 10.1172/JCI 116936

Massey, S. C., Rockne, R. C., Hawkins-Daarud, A., Gallaher, J., Anderson, A. R. A., Canoll, P., et al. (2018). Simulating PDGF-driven glioma growth and invasion in an anatomically accurate brain domain. Bull. Math. Biol. 80, 1292-1309. doi: 10.1007/s11538-017-0312-3

Mazzoleni, S., Politi, L. S., Pala, M., Cominelli, M., Franzin, A., Sergi, L. S., Falini, A., et al. (2010). Epidermal growth factor receptor expression identifies functionally and molecularly distinct tumor-initiating cells in human glioblastoma multiforme and is required for gliomagenesis. Cancer Res. 70, 7500-7513. doi: 10.1158/0008-5472.CAN-10-2353
McGranahan, N., and Swanton, C. (2017). Clonal heterogeneity and tumor evolution: past, present, and the future. Cell 168, 613-628. doi: 10.1016/j.cell.2017.01.018

Moghadam, S. A., Abadi, A. M., and Mokhtari, S. (2015). Immunohistochemical analysis of CD34 expression in salivary gland tumors. J. Oral Maxillofac. Pathol. 19, 30-33. doi: 10.4103/0973-029X.157197

Molina, E. S., Pillat, M. M., Moura-Neto, V., Lah, T. T., and Ulrich, H. (2014). Glioblastoma stem-like cells: approaches for isolation and characterization. J. Cancer Stem Cell Res. 1:1. doi: 10.14343/JCSCR.2014.2e1007

Murat, A., Migliavacca, E., Gorlia, T., Lambiv, W. L., Shay, T., Hamou, M., Tribolet, N., et al. (2008). Stem cell-related 'self-renewal' signature and high epidermal growth factor receptor expression associated with resistance to concomitant chemoradiotherapy in glioblastoma. J. Clin. Oncol. 26, 3015-3024. doi: 10.1200/JCO.2007.15.7164

Naujokat, C. (2014). Monoclonal antibodies against human cancer stem cells. Immunotherapy 6, 290-308. doi: 10.2217/imt.14.4

Nguyen, R., Perfetto, S., Mahnke, Y. D., Chattopadhyay, P., and Roederer, M. (2013). Quantifying spillover spreading for comparing instrument performance and aiding in multicolor panel design. Cytometry 83, 306-15. doi: $10.1002 /$ cyto.a.22251

Nielsen, J. S., and McNagny, K. M. (2008). Novel functions of the CD34 family. J. Cell Sci. 121, 3683-3692. doi: 10.1242/jcs.037507

Niepel, M., Spencer, S. L., and Sorger, P. K. (2009). Non-genetic cell-to-cell variability and the consequences for pharmacology. Curr. Opin. Chem. Biol. 13, 556-561. doi: 10.1016/j.cbpa.2009.09.015

Pallini, R., Ricci-Vitiani, L., Montano, N., Mollinari, C., Biffoni, M., Cenci, T., et al. (2011). Expression of the stem cell marker CD133 in recurrent glioblastoma and its value for prognosis. Cancer 117, 162-174. doi: 10.1002/cncr.25581

Patel, A. P.,Tirosh, I., Trombetta, J. J., Shalek, A. K., Gillespie, S. M., Wakimoto, H., Cahill, D. P., et al. (2014). Single-cell RNA-Seq highlights intratumoral heterogeneity in primary glioblastoma. Science 344, 1396-1401. doi: 10.1126/science.1254257

Patenaude, A., Parker, J., and Karsan, A. (2010). Involvement of endothelial progenitor cells in tumor vascularization. Microvasc. Res. 79, 217-223. doi: 10.1016/j.mvr.2010.01.007

Pavoine, S., and Dolédec, S. (2005). The apportionment of quadratic entropy: a useful alternative for partitioning diversity in ecological data. Environ. Ecol. Stat. 12, 125-138. doi: 10.1007/s10651-005-1037-2

Pennock, S., Kim, L. A., and Kazlauskas., A. (2016). Vascular endothelial cell growth factor A acts via platelet-derived growth factor receptor $\alpha$ to promote viability of cells enduring hypoxia. Mol. Cell. Biol. 36, 2314-2327. doi: 10.1128/MCB.01019-15

Plate, K. H., Breier, G., Farrell, C. L., and Risau, W. (1992). Platelet-derived growth factor receptor-beta is induced during tumor development and upregulated during tumor progression in endothelial cells in human gliomas. Lab. Invest. 67, 529-534.

Plate, K. H., Breier, G., Weich, H. A., Mennel, H. D., and Risau, W. (1994). Vascular endothelial growth factor and glioma angiogenesis: coordinate induction of VEGF receptors, distribution of vegf protein and possible in vivo regulatory mechanisms. Int. J. Cancer. 59, 520-529. doi: 10.1002/ijc.2910590415

Popescu, A. M., Alexandru, O., Brindusa, C., Purcaru, S. O., Tache, D. E., Tataranu, L. G., et al. (2015). Targeting the VEGF and PDGF signaling pathway in glioblastoma treatment. Int. J. Clin. Exp. Pathol. 8, 7825-7837.

Potts, S. J., Krueger, J. S., Landis, N. D., Eberhard, D. A., Young, G. D., Schmechel, S. C., et al. (2012). Evaluating tumor heterogeneity in immunohistochemistry-stained breast cancer tissue. Lab. Invest. 92, 1342-1357. doi: 10.1038/labinvest.2012.91

Qazi, M. A., Vora, P., Venugopal, C., Sidhu, S. S., Moffat, J., Swanton, C., et al. (2017). Intratumoral heterogeneity: pathways to treatment resistance and relapse in human glioblastoma. Ann. Oncol. 28, 1448-1456. doi: 10.1093/annonc/mdx169

Raftery, A. E. (1995). Bayesian model selection in social research. Sociol. Methodol. 25, 111. doi: $10.2307 / 271063$

Raines, E. W., Bowen-Pope, D. F., and Ross, R. (1991). "Platelet-derived growth factor," in Peptide Growth Factors and Their Receptors I, eds M. B. Sporn and A. B. Roberts (New York, NY: Springer), 173-262.

Rao, C. R. (1982). Diversity and dissimilarity coefficients: a unified approach. Theor. Popul. Biol. 21, 24-43. 
Rich, J. N., and Bigner, D. D. (2004). Development of novel targeted therapies in the treatment of malignant glioma. Nat. Rev. Drug Discov. 3, 430-446. doi: $10.1038 / \operatorname{nrd} 1380$

Rocha-Martins, M., Njaine, B., and Silveira, M. S. (2012). Avoiding pitfalls of internal controls: validation of reference genes for analysis by QRT-PCR and western blot throughout rat retinal development. PLoS ONE 7:e43028. doi: 10.1371 /journal.pone. 0043028

Ruch, C., Skiniotis, G., Steinmetz, M. O., Walz, T., and Ballmer-Hofer, K. (2007). Structure of a VEGF-VEGF receptor complex determined by electron microscopy. Nat. Struct. Mol. Biol. 14, 249-250. doi: 10.1038/nsmb1202

Sangar, V., Funk, C. C., Kusebauch, U., Campbell, D. S., Moritz, R. L., and Price, N. D. (2014). Quantitative proteomic analysis reveals effects of epidermal growth factor receptor (EGFR) on invasion-promoting proteins secreted by glioblastoma cells. Mol. Cell. Proteomics 13, 2618-2631. doi: $10.1074 /$ mcp.M114.040428

Sarabipour, S., and Hristova, K. (2016). Mechanism of FGF receptor dimerization and activation. Nat. Commun. 7:10262. doi: 10.1038/ncomms10262

Sarabipour, S., Ballmer-Hofer, K., and Hristova, K. (2016). VEGFR-2 conformational switch in response to ligand binding. Elife 5:e13876. doi: 10.7554/eLife.13876

Sarkaria, J. N., Yang, L., Grogan, P. T., Kitange, G. J., Carlson, B. L., Schroeder, M. A., Galanis, E., et al. (2007). Identification of molecular characteristics correlated with glioblastoma sensitivity to EGFR Kinase inhibition through use of an intracranial xenograft test panel. Mol. Cancer Ther. 6, 1167-1174. doi: 10.1158/1535-7163.MCT-06-0691

Saunders, N. A., Simpson, F., Thompson, E. W., Hill, M. M., Endo-Munoz, L., Leggatt, G., et al. (2012). Role of intratumoural heterogeneity in cancer drug resistance: molecular and clinical perspectives. EMBO Mol. Med. 4, 675-684. doi: $10.1002 / \mathrm{emmm} .201101131$

Schonberg, D. L., Lubelski, D., Miller, T. E., and Rich, J. N. (2014). Brain tumor stem cells: molecular characteristics and their impact on therapy. Mol. Aspects Med. 39, 82-101. doi: 10.1016/j.mam.2013.06.004

Seymour, T., Nowak, A., and Kakulas, F. (2015). Targeting aggressive cancer stem cells in glioblastoma. Front. Oncol. 5:159. doi: 10.3389/fonc.2015.00159

Shi, Q., Qin, L., Wei, W., Geng, F., Fan, R., Shin, Y. S., et al. (2012). Single-cell proteomic chip for profiling intracellular signaling pathways in single tumor cells. Proc. Natl. Acad. Sci. U.S.A. 109, 419-424. doi: 10.1073/pnas.1110865109

Shibuya, M. (2014). VEGF-VEGFR signals in health and disease. Biomol. Ther. 22, 1-9. doi: 10.4062/biomolther.2013.113

Shojaei, F., and Ferrara, N. (2008). Role of the microenvironment in tumor growth and in refractoriness/resistance to anti-angiogenic therapies. Drug Resist. Updates 11, 219-230. doi: 10.1016/j.drup.2008.09.001

Simons, M., Gordon, E., and Claesson-Welsh, L. (2016). Mechanisms and regulation of endothelial VEGF receptor signalling. Nat. Rev. Mol. Cell Biol. 17, 611-625. doi: 10.1038/nrm.2016.87

Simonson, A. B., and Schnitzer, J. E. (2007). Vascular proteomic mapping in vivo. J. Thromb. Haemostasis 5, 183-187. doi: 10.1111/j.1538-7836.2007.02551.x

Singh, S. K., Hawkins, C., Clarke, I. D., Squire, J. A., Bayani, J., Hide, T., et al. (2004). Identification of human brain tumour initiating cells. Nature 432, 396-401. doi: 10.1038/nature03128

Smith, C. L., Kilic, O., Schiapparelli, P., Guerrero-Cazares, H., Kim, D., SedoraRoman, N. I., et al. (2016). Migration phenotype of brain-cancer cells predicts patient outcomes. Cell Rep. 15, 2616-2624. doi: 10.1016/j.celrep.2016.05.042

Snuderl, M., Fazlollahi, L., Le, L. P., Nitta, M., Zhelyazkova, B. H., Davidson, C. J., Akhavanfard, S., et al. (2011). Mosaic amplification of multiple receptor tyrosine kinase genes in glioblastoma. Cancer Cell 20, 810-817. doi: 10.1016/j.ccr.2011.11.005

Soares, A. B., Juliano, P. B., Araujo, V. C., Metze, K., and Altemani, A. (2007). Angiogenic switch during tumor progression of carcinoma expleomorphic adenoma. Virchows Arch. 451, 65-71. doi: 10.1007/s00428-007$0438-\mathrm{z}$

Soda, Y., Marumoto, T., Friedmann-Morvinski, D., Soda, M., Liu, F., Michiue, H., Pastorino, S., et al. (2011). Transdifferentiation of glioblastoma cells into vascular endothelial cells. Proc. Natl. Acad. Sci. U.S.A. 108, 4274-4280. doi: 10.1073/pnas. 1016030108

Soeda, A., Hara, A., Kunisada, T., Yoshimura, S., Iwama, T., and Park., D. M. (2015). The evidence of glioblastoma heterogeneity. Sci. Rep. 5:7979. doi: $10.1038 /$ srep07979
Soeda, A., Inagaki, A., Oka, N., Ikegame, Y., Aoki, H., Yoshimura, S., et al. (2008). Epidermal growth factor plays a crucial role in mitogenic regulation of human brain tumor stem cells. J. Biol. Chem. 283, 10958-10966. doi: 10.1074/jbc.M704205200

Sorkin, A., and Duex, J. E. (2010). Quantitative analysis of endocytosis and turnover of epidermal growth factor (EGF) and EGF receptor. Curr. Protoc. Cell Biol. Chapter 15:Unit 15.14. doi: 10.1002/0471143030.cb1514s46

Spitzer, M. H., and Nolan, G. P. (2016). Mass cytometry: single cells, many features. Cell 165, 780-791. doi: 10.1016/j.cell.2016.04.019

Steinkamp, M. P., Low-Nam, S. T., Yang, S., Lidke, K. A., Lidke, D. S., and Wilson, B. S. (2014). ErbB3 is an active tyrosine kinase capable of homo- and heterointeractions. Mol. Cell. Biol. 34, 965-977. doi: 10.1128/MCB.01605-13

Szerlip, N. J., Pedraza, A., Chakravarty, D., Azim, M., McGuire, J., Fang, Y., Ozawa, T., et al. (2012). Intratumoral heterogeneity of receptor tyrosine kinases EGFR and PDGFRA amplification in glioblastoma defines subpopulations with distinct growth factor response. Proc. Natl. Acad. Sci. U.S.A. 109, 3041-3046. doi: 10.1073/pnas.1114033109

Szopa, W., Burley, T. A., Kramer-Marek, G., and Kaspera, W. (2017). Diagnostic and therapeutic biomarkers in glioblastoma: current status and future perspectives. Biomed. Res. Int. 2017:8013575. doi: 10.1155/2017/ 8013575

Taniguchi, Y., Choi, P. J., Li, G., Chen, H., Babu, M., Hearn, J., et al. (2010). Quantifying E. coli proteome and transcriptome with single-molecule sensitivity in single cells. Science 329, 533-538. doi: 10.1126/science.1188308

Tirosh, I., Izar, B., Prakadan, S. M., Wadsworth, M. H., Treacy, D., Trombetta, J. J., Rotem, A., et al. (2016). Dissecting the multicellular ecosystem of metastatic melanoma by single-cell RNA-seq. Science 352, 189-196. doi: 10.1126/science.aad0501

Verhaak, R. G., Hoadley, K. A., Purdom, E., Wang, V., Qi, Y., Wilkerson, M. D., Miller, C. R., et al. (2010). Integrated genomic analysis identifies clinically relevant subtypes of glioblastoma characterized by abnormalities in PDGFRA, IDH1, EGFR, and NF1. Cancer Cell 17, 98-110. doi: 10.1016/j.ccr.2009. 12.020

Vigelsø, A., Dybboe, R., Hansen, C. N., Dela, F., Helge, J. W., and Grau, A. G. (2015). GAPDH and $\beta$-actin protein decreases with aging, making stainfree technology a superior loading control in western blotting of human skeletal muscle. J. Appl. Physiol. 118, 386-394. doi: 10.1152/japplphysiol.008 40.2014

Volinsky, N., and Kholodenko, B. N. (2013). Complexity of receptor tyrosine kinase signal processing. Cold Spring Harb. Perspect. Biol. 5:a009043. doi: 10.1101/cshperspect.a009043

Weddell, J. C., and Imoukhuede, P. I. (2014). Quantitative characterization of cellular membrane-receptor heterogeneity through statistical and computational modeling. PLoS ONE 9:e97271. doi: 10.1371/journal.pone.0097271

Weddell, J. C., and Imoukhuede, P. I. (2017). Integrative meta-modeling identifies endocytic vesicles, late endosome and the nucleus as the cellular compartments primarily directing RTK signaling. Integr. Biol. 9, 464-484. doi: 10.1039/C7IB00011A

Weddell, J. C., and Imoukhuede, P. I. (2018). Computational systems biology for the VEGF family in angiogenesis. Encycloped. Cardiovasc. Res. Med. 659-676. doi: 10.1016/B978-0-12-809657-4.99548-6

Wehland, M., Bauer, J., Magnusson, N. E., Infanger, M., and Grimm, D. (2013). Biomarkers for anti-angiogenic therapy in cancer. Int. J. Mol. Sci. 14, 9338-9364. doi: 10.3390/ijms14059338

Wei, W., Shin, Y. S., Xue, M., Matsutani, T., Masui, K., Yang, H., Ikegami, S., et al. (2016). Single-cell phosphoproteomics resolves adaptive signaling dynamics and informs targeted combination therapy in glioblastoma. Cancer Cell 29, 563-573. doi: 10.1016/j.ccell.2016.03.012

Weickhardt, A. J., Williams, D. S., Lee, C. K., Chionh, F., Simes, J., Murone, C., Wilson, K., et al. (2015). Vascular endothelial growth factor D expression is a potential biomarker of bevacizumab benefit in colorectal cancer. Br. J. Cancer 113, 37-45. doi: 10.1038/bjc.2015.209

Weis, S. M., and Cheresh, D. A. (2011). Tumor angiogenesis: molecular pathways and therapeutic targets. Nat. Med. 17, 1359-1370. doi: 10.1038/nm.2537

Werner, S., Hofschneider, P. H., Heldin, C. H., Ostman, A., and Roth, W. K. (1990). Cultured kaposi's sarcoma-derived cells express functional PDGF A-type and B-type receptors. Exp. Cell Res. 187, 98-103. 
Wheeler, D. L., Dunn, E. F., and Harari, P. M. (2010). Understanding resistance to EGFR inhibitors[mdash]impact on future treatment strategies. Nat. Rev. Clin. Oncol. 7, 493-507. doi: 10.1038/nrclinonc.2010.97

Wheeless, L. L., Coon, J. S., Cox, C., Deitch, A. J., White, R. W. D., Koss, L. G., Melamed, M., et al. (1989). Measurement variability in DNA flow cytometry of replicate samples. Cytometry 10, 731-738. doi: 10.1002/cyto.990 100610

Wu, F. T. H., Stefanini, M. O., Gabhann, F. M., Kontos, C. D., Annex, B. H., and Popel, A. S. (2010). A systems biology perspective on SVEGFR1: its biological function, pathogenic role and therapeutic use. J. Cell. Mol. Med. 14, 528-552. doi: 10.1111/j.1582-4934.2009.00941.x

Yadav, V. N., Altshuler, D., Kadiyala, P., Zamler, D., Comba, A., Appelman, H., et al. (2018). Molecular ablation of tumor blood vessels inhibits therapeutic effects of radiation and bevacizumab. Neuro-Oncology, April. doi: 10.1093/neuonc/noy055
Zoltán, B. (2005). Rao's quadratic entropy as a measure of functional diversity based on multiple traits. J. Veg. Sci. 16, 533-540. doi: 10.1111/j.1654-1103.2005.tb02393.x

Conflict of Interest Statement: The authors declare that the research was conducted in the absence of any commercial or financial relationships that could be construed as a potential conflict of interest.

Copyright (C) 2018 Chen, Le, Harley and Imoukhuede. This is an open-access article distributed under the terms of the Creative Commons Attribution License (CC BY). The use, distribution or reproduction in other forums is permitted, provided the original author(s) and the copyright owner(s) are credited and that the original publication in this journal is cited, in accordance with accepted academic practice. No use, distribution or reproduction is permitted which does not comply with these terms. 